\title{
Lei de Hooke
}

Miguel Ferreira

Faculdade de Ciências da Universidade do Porto

miguel.cfer@gmail.com

\section{CITAÇÃO}

Ferreira, M. (2014)

Lei de Hooke,

Rev. Ciência Elem., V2 (01):103.

doi.org/10.24927/rce2014.103

\section{EDITOR}

José Ferreira Gomes,

Universidade do Porto

\section{RECEBIDO EM}

20 de julho de 2011

\section{ACEITE EM}

03 de outubro de 2011

\section{PUBLICADO EM}

03 de outubro de 2011

\section{COPYRIGHT}

(C) Casa das Ciências 2019.

Este artigo é de acesso livre, distribuído sob licença Creative

Commons com a designação CC-BY-NC-SA 4.0, que permite a utilização e a partilha para fins não comerciais, desde que citado o autor e a fonte original do artigo.

\section{rce.casadasciencias.org}

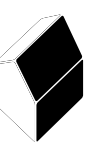

Quando se aplica uma tensão mecânica num corpo este deforma-se.

A relação entre a deformação e a tensão depende em que regime de deformação se encontra o corpo. Num regime elástico e num meio isotrópico, a tensão $(\tau)$ e a deformação relativa $(\epsilon)$ são diretamente proporcionais:

$$
\tau=\mathrm{Y} \epsilon
$$

sendo $Y$ o módulo de elasticidade, conhecido por módulo de Young. A equação anterior constitui a formalização da lei de Hooke, que é adequada para descrever o compostamento elástico de corpos desde que as deformações sejam pequenas (regime linear ou elástico). 0 módulo de Young, expresso em pascal no SI, é característico do material de que é feito o corpo.

Para estados de formação apreciáveis, a lei de Hooke não é válida e diz-se que o corpo se encontra no regime plástico.

\section{Mola}

No caso particular de uma mola, o elongamento $(\Delta \mathrm{x})$ é diretamente proporcional à intensidade da força aplicada:

$$
\mathrm{F}=\mathrm{k} \Delta \mathrm{x}
$$

em que $k$ é a constante elástica da mola.

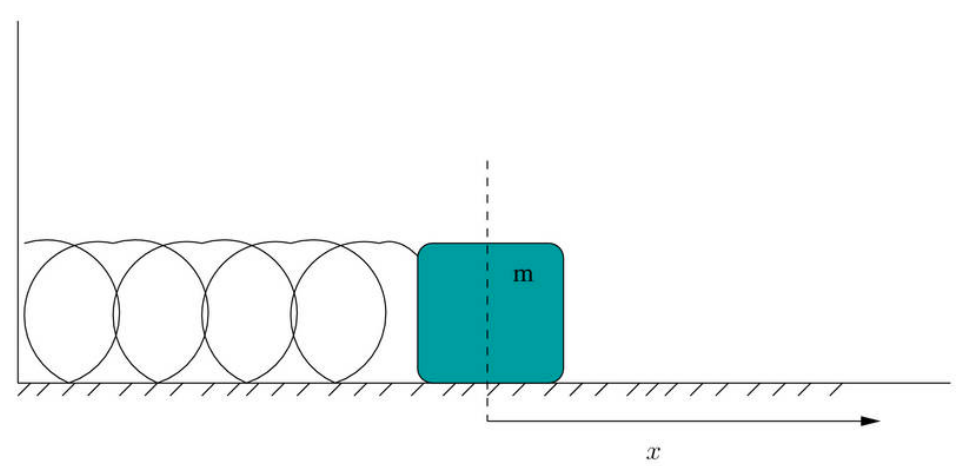

FIGURA 1. Representação esquemática de uma mola na sua posição de equilíbrio. 0 deslocamento, x, é medido a partir da sua posição de equilíbrio. 